\title{
Locking suture repair versus ligament augmentation-a biomechanical study regarding the treatment of acute lateral collateral ligament injuries of the elbow
}

\author{
Nadine Ott ${ }^{1} \cdot$ Arne Harland $^{1} \cdot$ Fabian Lanzerath $^{1} \cdot$ Tim Leschinger $^{1} \cdot$ Michael Hackl $^{1} \cdot$ Kilian Wegmann $^{1}$. \\ Lars Peter Müller ${ }^{1}$
}

Received: 19 June 2021 / Accepted: 1 January 2022 / Published online: 22 January 2022

(c) The Author(s) 2022

\begin{abstract}
Background Lateral collateral ligament (LCL) tears are frequently observed in fractures and dislocations of the elbow. Recent biomechanical evidence suggests that additional ligament augmentation may improve repair stability. The aim of this biomechanical in-vitro study was to compare the resistance of a locking suture repair of the LCL with a ligament augmentation technique.

Material and methods Eight fresh frozen cadaveric elbows were evaluated for stability against varus/posterolateral rotatory forces $(3 \mathrm{Nm})$. A strain gauge $(\mu \mathrm{m} / \mathrm{m}$; negative values) was placed at the origin and insertion of the lateral ulnar collateral ligament (LUCL) and cyclic loading was performed for 1000 cycles. We analyzed three distinct scenarios: (A) native LCL, (B) locking transosseou suture repair of the LCL, (C) simple LCL repair with additional ligament augmentation of the LUCL. Results The mean measured strain was $-416.1 \mu \mathrm{m} / \mathrm{m}(\mathrm{A}),-618 \mu \mathrm{m} / \mathrm{m}$ (B) and $-288.5 \mu \mathrm{m} / \mathrm{m}(\mathrm{C})$ with the elbow flexion at $90^{\circ}$; the strain was significantly higher in scenario B compared to C $(p=.01)$. During the cyclic load $(1000)$ the mean measured strain was $-523.1 \mu \mathrm{m} / \mathrm{m}$ (B) and $-226.3 \mu \mathrm{m} / \mathrm{m}$ (C) with the elbow flexion at $60^{\circ}$; the strain was significantly higher in scenario B compared to $\mathrm{C}(p=.01)$. No significant difference between the first and the last cycles was observed $(p=.09 ; p=.07)$. One failure of the LCL repair was observed after 1000 cycles; none of the ligament augmentations failed. Conclusion Ligament augmentation (C) provides higher resistance compared to the native LCL (A) and to the locking suture repair technique (B). Both techniques, however, hold up during 1000 cycles. While ligament augmentation might enhance the primary stability of the repair, future clinical studies have to show whether this increase in resistance leads to negative effects like higher rates of posttraumatic elbow stiffness.
\end{abstract}

Level of evidence Basic science study, biomechanics.

Keywords Posterolateral rotatory instability $\cdot$ LCL tear $\cdot$ LCL repair $\cdot$ Ligament augmentation $\cdot$ Stability $\cdot$ Cyclic loading

\section{Introduction}

Lateral collateral ligament (LCL) injuries are frequent elbow pathologies in elbow trauma. The elbow is the second most dislocated joint of the upper extremity after the shoulder [1]. In case of ligamentous dislocations, LCL injuries are most frequently accompanied lesions. Simple ligamentous

Nadine Ott

Nadine.ott@uk-koeln.de

1 Department of Trauma and Orthopedic Surgery, University Hospital Cologne and Faculty of Medicine, University of Cologne, Kerpener Street 62, 50937 Cologne, Germany lesions can be treated conservatively [2]. However, there is a subset of patients who experience recurrent instability or subluxation; a posterolateral rotatory instability (PLRI) could result [3-5]. PLRI of the elbow is associated with an insufficient lateral collateral ligament complex (LCL) [6-9]. When surgical treatment is performed, LCL repair is crucial to avoid persisting posterolateral rotatory instability. Recently, ligament augmentation techniques have gained popularity [2, 9-19].

Besides primary repair and autograft or allograft reconstructions, the use of ligament brace techniques has been studied and reported to be stronger biomechanically $[1,10$, $13-15,19-21]$. The goal of all these procedures is an anatomic reconstruction of the LCL for restoration of functional 
elbow stability and ligament repair with a locking transosseous suture is still preferred by many surgeons [22].

However, to the Authors knowledge, there have been no biomechanical in-vitro study that evaluated the use of additional ligament augmentation and this LCL repair according to the locking transosseous suture technique [22] compared to the native LCL. Therefore, the present study aimed to analyze the resistance of primary repair, additional ligament augmentation of LCL and the native LCL after 1000 cycles rotational load.

\section{Material and methods}

\section{Specimen preparation}

For this biomechanical study, nine fresh frozen cadaveric elbows from 3 male and 6 female donors were available. The mean age at the time of death was 73 (min. 65, max. 91, SD 12 years). The specimens were stored at $-20^{\circ} \mathrm{C}$ and thawed at room temperature 12-14 $\mathrm{h}$ before dissection and biomechanical testing. Fluoroscopic and clinical examinations were performed to exclude specimens with osteoarthritis or signs of previous surgery and trauma. The soft tissue of the proximal humerus and the forearm was preserved.

Strain of the LUCL was measured indirectly via strain gauges. A strain gauge (4-wire; $350 \mathrm{Ohm}$; Vishay Inc., Malvern, PA, USA) was fixed on top of a custom-made sensor (Steel, Dx 51) with M-Bond (Vishay Inc., Malvern, PA, USA); the sensor takes the form of a omega. The form of the omega allows the efficient transfer of the applied force through the strain gauge (Fig. 1A). While the measurement the deformation of the sensor was transferred through the strain gauge. A calibration of each strain gauge was performed. Axial deformation was transferred through the strain gauges and therewith resulted in a deflection of the measuring device, which was digitally documented via a software in $\mu \mathrm{m} / \mathrm{m}$ (MGCplus Fa. HBM, Darmstadt, Germany). To reduce measurement errors, a 4-wire strain gauge was used.

The sensor augmented with a strain gauge (4-wire $120 \Omega$, Vishay Inc., Malvern, PA, USA) was fixed along the course of the LUCL with the help of threaded $\mathrm{k}$-wires placed at the origin and insertion of the LUCL (Fig. 1B). Posterolateral rotation of the forearm resulted in a deformation of the sensor and the sensor transferred the applied force through the strain gauge.

\section{Scenario A}

In scenario A, the ligaments and the fascia of the forearm remained intact. After testing the specimens in the intact state, a lateral Kocher approach was performed and the LCL along with the common extensor origin were sharply detached from the distal humerus.

\section{Scenario B}

In scenario B, a locking suture repair of the LCL was performed, modified according to the technique published in Green's chapter [22]: first, two suture anchors (FASTak, $2.4 \mathrm{~mm}$, Arthrex Inc., Naples, FL, USA) were placed in the center of rotation of the capitulum and in the lateral supracondylar ridge. A locking suture was then placed in the LUCL from proximal to distal over the course of $3 \mathrm{~cm}$ with one suture limb of the suture anchor placed in the center of rotation. On the way back, the radial collateral ligament and the annular ligament were incorporated in the repair to close the interval between the RCL and the LUCL. A sliding knot was performed to secure the LCL back to its origin while holding the elbow in $90^{\circ}$ of flexion and in full pronation. The

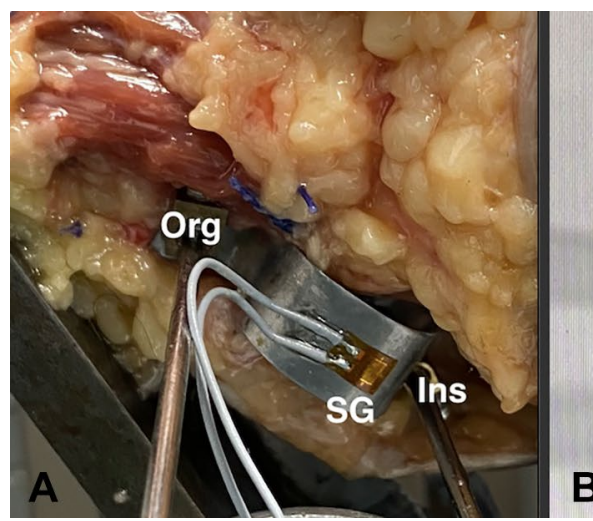

Fig. 1 The titanium omega augmented with a strain gauge, SG, (4-wire $120 \Omega$, Vishay Inc., Malvern, PA, USA) was fixed at the origin (Org) and insertion (Ins) of the LUCL (A). A posterolateral rotatory instability with ulno-humeral displacement resulted in a defor- mation of the fixed omega. By fluoroscopy the anatomical position was verified (B); in each scenario closure of the fascia overlying the Kocher interval was performed (PDS 0, Ethicon Inc., Bridgewater, NJ, USA) 
second suture anchor was used for refixation of the common extensor origin with a mattress suture (Fig. 2). Closure of the fascia overlying the Kocher interval was performed (PDS 0, Ethicon Inc., Bridgewater, NJ, USA).

\section{Scenario C}

In scenario $\mathrm{C}$, two drill holes were employed: one in the capitulum at the center of rotation; and another in the proximal ulna directly posterior to the supinator crest and approximately $1 \mathrm{~cm}$ distal to the articular surface of the radial head. A suture anchor loaded with a suture tape (3.5 mm PEEK SwiveLock anchor; FiberTape ${ }^{\circledR}$, Arthrex Inc., Naples, FL, USA) was inserted in the distal drill hole. The lateral capsule was closed with interrupted 2-0 sutures. The suture tape was then spanned over the lateral capsule. The entry point of the tape into the humeral bone tunnel was marked with a pen. In the next step, fixation of the tape was performed by inserting a second suture anchor into the distal humerus with respect to the pen marking in order not to over-tighten the augmentation. The remaining suture ends of the suture tape were used to repair the LCL and the common extensor origin back to bone with a simple suture. The tape was then spanned over the LUCL with elbow at $30^{\circ}$ flexion and a pronated forearm. To control the tight, the sutures were marked at the laser line. The anchor was placed at the marked sutures and fixed at the proximal drill hole (Fig. 3). Identically to scenario B, the fascia was closed.

To keep the measurements errors low, a 4-wire strain gauge was used.

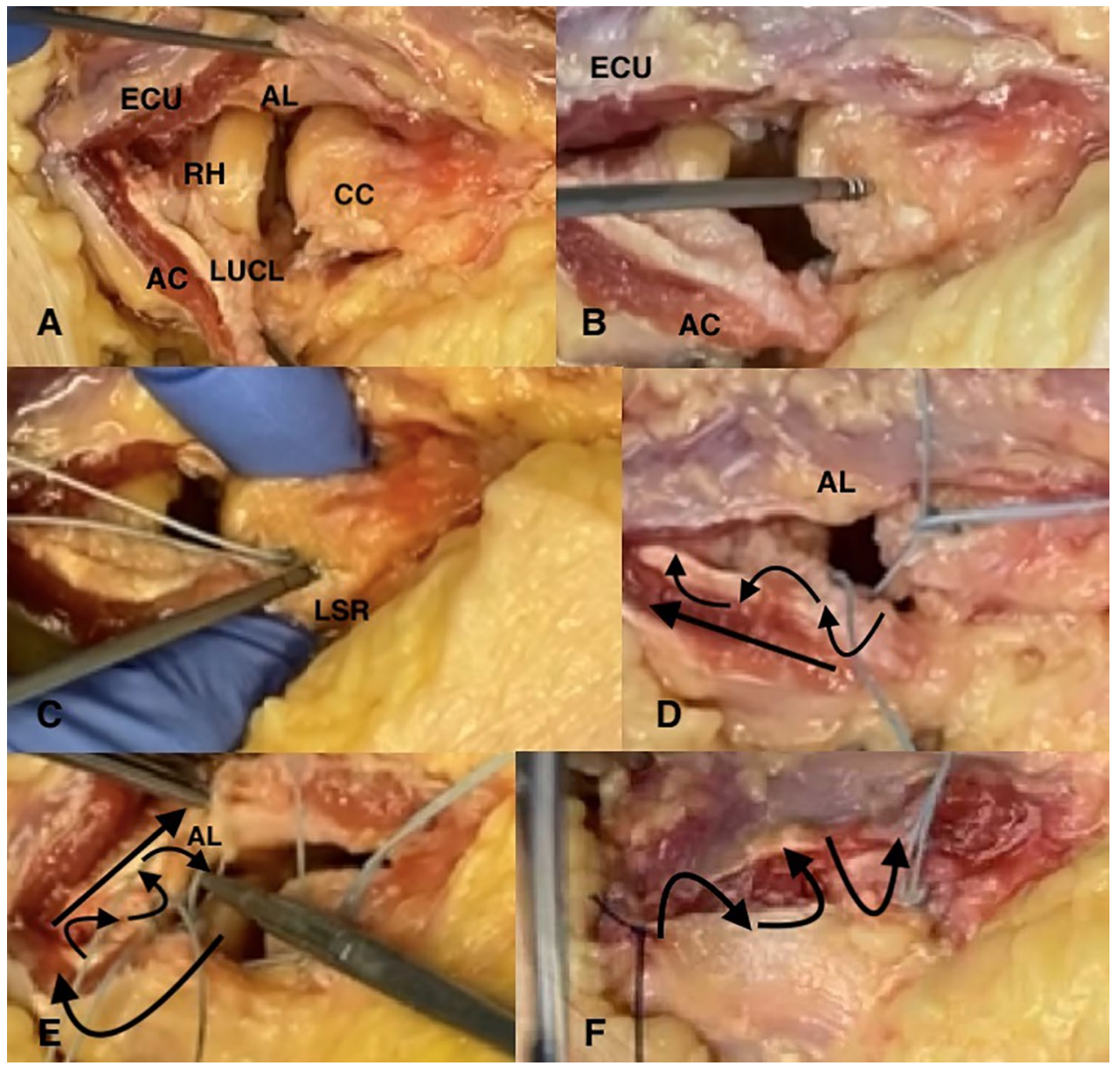

Fig. 2 Lateral Kocher approach was performed; extensor carpi ulnaris (ECU), aconeus muscle (AC), anular ligament (AL); humeral isometric point was located by identifying the intersection point in which the lateral condyle is bisected by a line from the center of the radial head $(\mathrm{RH})$ both in $90^{\circ}$ of flexion and extension $(\mathbf{A})$. In contrast to the technique described in Green's chapter [22], we have used two $2.4 \mathrm{~mm}$ FASTak (Fa. Arthrex). The first was placed at the axis of motion (the center of the arc of curvature of the capitulum; CC) (B) and the second placed posterior to the lateral supracondylar ridge; LSR (C). Suture passers are placed to facilitate the repair. A locking suture technique is employed to gain a secure hold of LUCL (D). The interval between radial collateral and LUCL and the annular ligament (AL) are closed at this suture is brought back to the lateral epicondyle (E). The ligament sutures are pulled into the FASTak in the distal humerus with maintaining the forearm in pronation and avoiding varus forces while tying the sutures $(\mathbf{F})$ 


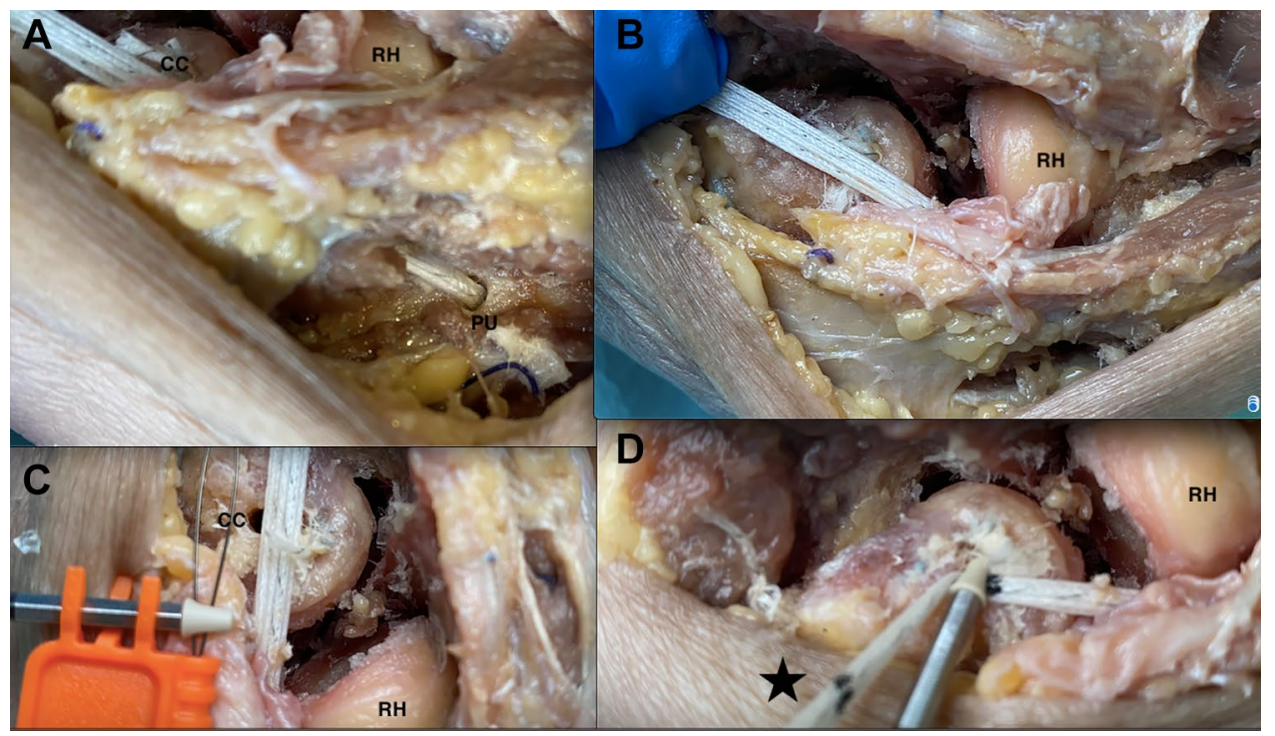

Fig. 3 two drill holes were employed: one in the capitulum at the center of rotation (CC); and another in the proximal ulna (PU) directly posterior to the supinator crest and approximately $1 \mathrm{~cm}$ distal to the articular surface of the radial head (RH) (A). A suture anchor loaded with a suture tape (3.5 mm PEEK SwiveLock anchor; FiberTape $^{\circledR}$, Arthrex Inc., Naples, FL, USA) was inserted in the distal drill hole. The lateral capsule was closed with interrupted 2-0 sutures. The suture tape was then spanned over the lateral capsule (B). The entry point of the tape into the humeral bone tunnel was

\section{Biomechanical testing set-up}

The humeral shaft was secured to a custom-made testing fixture with two mounting clamps. The hinged testing fixture allowed for movement of the elbow joint from $60^{\circ}$ to $90^{\circ}$ and was mounted onto a servohydraulic universal testing machine (ZwickRoell; Ulm, Germany). A mounting bolt was securely fixed to the lateral side of the ulnar shaft $10 \mathrm{~cm}$ distal to the center of rotation. A synthetic wire connected the bolt to the mobile traverse of the testing machine. Reels were used for deflection of the wire. Thereby, upward movement of the mobile traverse resulted in posterolateral rotatory/varus force, depending on wire deflection (Fig. 4). This biomechanical testing set-up was used in previous studies $[8,9,23]$. Stability in each scenario was evaluated with the elbow in $60^{\circ}$ and $90^{\circ}$ of flexion.

A maximal rotational moment of $3 \mathrm{Nm}$ at $0.5 \mathrm{~Hz}$ was applied. Each scenario was performed with elbow flexion at $60^{\circ}$ and $90^{\circ}$ with 10 rotational cycles. In scenario B and C, the strain was measured with elbow flexion at $60^{\circ}$ through 1000 rotational cycles. The resulting deformation of the sensor was transferred through the strain gauge $(\mu \mathrm{m} / \mathrm{m})$. This testing method was designed to simulate the immediate postoperative period when failure is most likely to occur by repetitive movements. By performing temporary arthrodesis of the distal radio- ulnar joint with two 2.0-mm Kirschner marked with a pen. In the next step, fixation of the tape was performed by inserting a second suture anchor into the distal humerus with respect to the pen marking (black star) in order not to overtighten the augmentation (C) The remaining suture ends of the suture tape were used to repair the LCL and the common extensor origin back to bone with a simple suture. The tape was then spanned over the LUCL with elbow at $30^{\circ}$ flexion and a pronated forearm. To control the tight, the sutures were marked at the laser line (D)

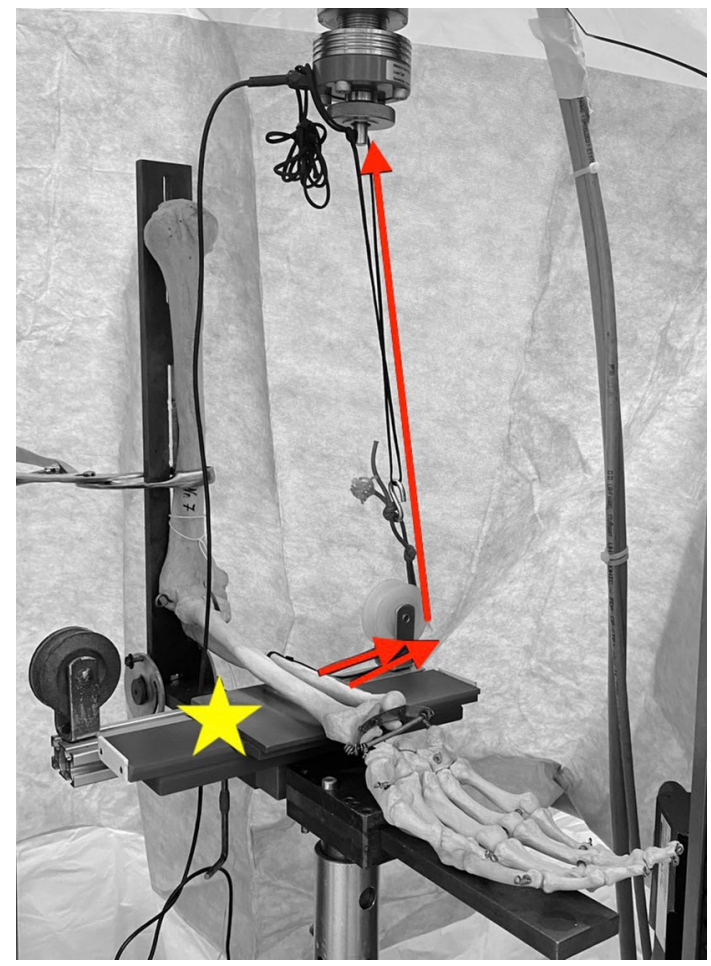

Fig. 4 upward movement of the mobile traverse (red arrows) resulted in posterolateral rotatory/varus force, depending on wire deflection (yellow star). This biomechanical testing set-up has been used by previous study $[8,9,23]$ 
wires, measurements could be obtained in supination. The specimen remained in the identically biomechanical testing set-up for each scenario. Thereby, measurement errors between each scenario were kept low. The repair techniques were performed by the senior author (L.P.M.).

In our biomechanical testing set-up, negative values of the strain gauge resulted in a deformation of the used omega.

\section{Statistical analysis}

The data collected were analyzed using the SPSS statistical program. Normal distribution was tested by Kolmogorov-Smirnov. A $t$ test and ANOVA-test was performed to detect any statistically significant differences. We used descriptive statistics to summarize the means and standard deviations. The level of significance was defined as a $p$ value of $<0.05$.

\section{Ethical considerations}

The local ethics committee approved this work and informed consent was obtained from each volunteer included in this study (Ethical Committee of the Medical Faculty of the University of Cologne-VT (No: 20-1369). This study followed the guidelines for experimental investigation with human subject required by our institution.

\section{Results}

Table 1 and Fig. 5 summarized the main results.

The mean measured strain was $-416.1 \mu \mathrm{m} / \mathrm{m}$ (A), $-618 \mu \mathrm{m} / \mathrm{m}$ (B) and $-288.5 \mu \mathrm{m} / \mathrm{m}$ (C) with the elbow flexion at $90^{\circ}$; the strain was significantly higher in scenario $\mathrm{B}$ compared to $\mathrm{C}(p=0.01)$. During the cyclic load the mean measured strain was $-523.1 \mu \mathrm{m} / \mathrm{m}$ (B) and $-226.3 \mu \mathrm{m} / \mathrm{m}$ (C) with the elbow flexion at $60^{\circ}$; the strain was significantly higher in scenario B compared to $\mathrm{C}(p=0.01)$. No significant difference between the first and the last cycles were observed $(p=0.09 ; p=0.07)$. In scenario $\mathrm{B}$, one failure after 1000 cycles was observed. The suture was closed, the ligament sutures which were pulled back to the FASTak lost their tightness.

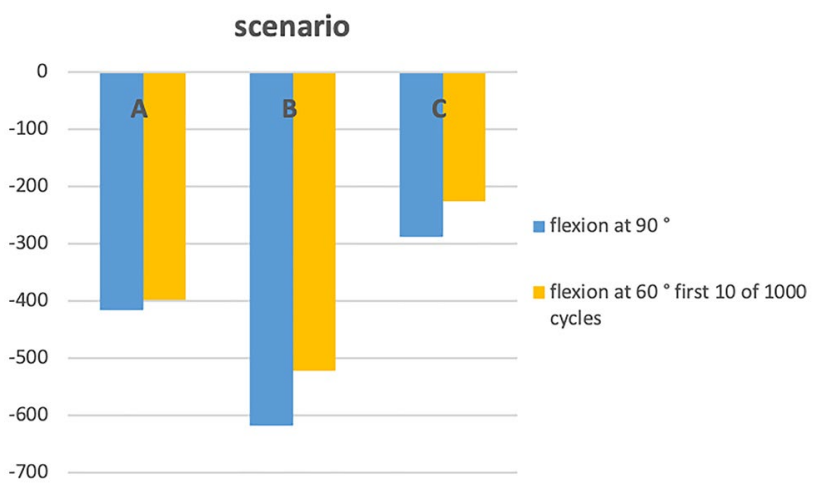

Fig. 5 overview of the results, $y$-axis presents the measured strain $(\mu \mathrm{m} / \mathrm{m})$ in scenario A (native), B (repair) and C (ligament augmentation) (x-axis)

In scenario $\mathrm{C}$, no failure of the ligament augmentation was detected.

\section{$90^{\circ}$ of elbow flexion}

In scenario A, the mean measured strain was $-416.1 \mu \mathrm{m} / \mathrm{m}$ (min. $84 \mu \mathrm{m} / \mathrm{m}$; max. $-950 \mu \mathrm{m} / \mathrm{m}$, SD $315.4 \mu \mathrm{m} / \mathrm{m}$ ). In scenario B, the mean measured strain was $-618 \mu \mathrm{m} / \mathrm{m}$ (min. $177 \mu \mathrm{m} / \mathrm{m}$; max. $-1065 \mu \mathrm{m} / \mathrm{m}$, SD $325.6 \mu \mathrm{m} / \mathrm{m}$ ) and in scenario $\mathrm{C}$, the mean measured strain was $-288.5 \mu \mathrm{m} / \mathrm{m}$ (min. $-11 \mu \mathrm{m} / \mathrm{m}$; max. $-740 \mu \mathrm{m} / \mathrm{m}$, SD $243.9 \mu \mathrm{m} / \mathrm{m})$.

\section{$60^{\circ}$ of elbow flexion}

In scenario A, the mean measured strain was $-399 \mu \mathrm{m} / \mathrm{m}$ (min. $-100 \mu \mathrm{m} / \mathrm{m}$; max. - $770 \mu \mathrm{m} / \mathrm{m}$; SD $219 \mu \mathrm{m} / \mathrm{m}$ ) during 10 cycles. In scenario $B$, in the first cycles of 1000 cycles the strain was $-523.1 \mu \mathrm{m} / \mathrm{m}$ (min. $-170 \mu \mathrm{m} / \mathrm{m}$; $\max .-660 \mu \mathrm{m} / \mathrm{m} ; \mathrm{SD} 149.6 \mu \mathrm{m} / \mathrm{m})$ and in the last cycles it was $-404.3 \mu \mathrm{m} / \mathrm{m}$ (min. $-85 \mu \mathrm{m} / \mathrm{m}$; max. $-760 \mu \mathrm{m} / \mathrm{m}$, SD $232.9 \mu \mathrm{m} / \mathrm{m}$ ). In scenario $\mathrm{C}$, in the first cycles of 1000 cycles the strain was $-226.3 \mu \mathrm{m} / \mathrm{m}$ (min. $-6 \mu \mathrm{m} / \mathrm{m}$; max. $-680 \mu \mathrm{m} / \mathrm{m}$; SD $244.8 \mu \mathrm{m} / \mathrm{m}$ ) and in the last cycles it was $-278 \mu \mathrm{m} / \mathrm{m}$ (min. $-65 \mu \mathrm{m} / \mathrm{m}$; max. $-650 \mu \mathrm{m} / \mathrm{m}$, SD $217.5 \mu \mathrm{m} / \mathrm{m})$.
Table 1 summarized the main results; measured strain in $\mu \mathrm{m} / \mathrm{m}$ in scenario $\mathrm{A}-\mathrm{C}$ and the position of the elbow with $p$ values

\begin{tabular}{|c|c|c|c|c|c|c|}
\hline & \multicolumn{3}{|l|}{ Scenario } & \multicolumn{3}{|c|}{$p$ value } \\
\hline & A (strain in $\mu \mathrm{m} / \mathrm{m}$ ) & $\mathrm{B}($ strain in $\mu \mathrm{m} / \mathrm{m})$ & $\mathrm{C}($ strain in $\mu \mathrm{m} / \mathrm{m})$ & $\mathrm{A} / \mathrm{B}$ & $\mathrm{B} / \mathrm{C}$ & $\mathrm{A} / \mathrm{C}$ \\
\hline \multicolumn{7}{|l|}{ Position of the elbow } \\
\hline Flexion at $90^{\circ}$ & -416.1 & -618 & -288 & .03 & .07 & .34 \\
\hline \multicolumn{7}{|l|}{ Flexion at $60^{\circ}$} \\
\hline First 10 of 1000 & -399 & -523.1 & -226.3 & .07 & .01 & .08 \\
\hline Last 10 of 1000 & & -404.2 & -278 & & .12 & \\
\hline
\end{tabular}




\section{Discussion}

The most important finding of our study is, that ligament augmentation of the LUCL shows significant less displacement compared to the native LCL and the locking suture repair technique [22]. After 1000 cycles no failures in the ligament augmentation group was observed. The ulnohumeral displacement by the deformation of the omega was not increased significantly during the 1000 loading cycles. In the repair group, macroscopic loosening of the locking suture was observed in one case following cyclic loading.

As mentioned previously, Melbourne et al. [19] showed that suture tape augmentation of the LUCL is associated with significantly higher load to failure than repair or reconstruction alone. They described a protective effect of the ligament augmentation on the underlying repaired ligament. This can be confirmed by the results of the present study.

Recently, Ellwein et al. [14] observed a higher load to failure after LUCL repair with additional ligament bracing than repair alone. In the present study, a load to failure was not performed. We used the strain gauge to evaluate the ulno-humeral displacement by the deformation of the omega continuously during 1000 cycles. Comparing the measured strain at the first 10 and the last 10 of 1000 cycles, no significant difference could be observed in the internal brace and the repair group.

Greiner et al. [21] published the clinical results after LUCL repair augmented with ligament bracing. Seventeen patients with acute or subacute posterolateral elbow instability as a result of dislocation or fracture dislocation were treated with open LUCL refixation and non-absorbable suture tape augmentation. The elbows were actively mobilized immediately after the operation and a maximum bracing period of 3 days. All patients were without recurrent instability at the time of follow-up. Despite rehab, range of motion was not very good at ten months. Patients in this study had a mean extension lag of $10^{\circ}$. While the re-operation rate was low. Their postoperative time to full mobilization was significantly lower than of other LUCL studies. Taking their observations, LUCL repair with ligament augmentation might shorten rehabilitation based on a resistance. However, Fraser et al. have shown that LCL repair using transosseous sutures is a useful technique to restore initial elbow kinematics [24].

Future research will need to clarify whether ligament augmentation leads to higher rates of postoperative elbow stiffness due to the augmentation, however, the LCL repair as well as the ligament augmentation hold up during 1000 cycles. Although, an increased displacement after 1000 cycle was measured in the ligament augmentation group. Our results have shown greater resistance in the ligament augmentation group.
Compared to the native LCL, the resistance of the ligament augmentation might be higher. So, it remains unknown whether higher resistance due to the increased rigidity of the repair might result in higher rates of postoperative elbow stiffness. Consequently, it may be not useful to perform additional ligament augmentation in every case of elbow instability. In our clinical experience, the decision for repair alone or additional augmentation was based on the severity of instability and the accompanied lesions.

The present study has several limitations. Firstly, the small sample size may pose the risk of a type two error. Due to the difficulty of procuring suitable cadaveric specimens, this problem is commonly encountered in biomechanical research. Another inherent weakness of cadaveric biomechanical studies is the age of the specimens relative to the patient population of interest. Finally, the study conditions do not accurately recreate the physiological reality that the studies portend to examine. However, to our knowledge, this is the first study which has remained all the soft tissues. The last drawback of the present study the cyclic loading (1000) just being performed in a single elbow position and single degree of freedom.

\section{Conclusion}

Ligament augmentation provides higher resistance compared to the native LCL and to the locking suture repair technique. Both techniques, however, hold up during 1000 cycles. While ligament augmentation might enhance the primary stability of the repair, future clinical studies have to show whether this increase in resistance leads to negative effects like higher rates of posttraumatic elbow stiffness.

Acknowledgements We thank Juergen Scharlack for his assistance with preparation and application of strain gauges in the current study design.

Funding Open Access funding enabled and organized by Projekt DEAL. Not applicable.

\section{Declarations}

Conflict of interest The authors, their immediate family, and any research foundation with which they are affiliated did not receive any financial payments or other benefits from any commercial entity related to the subject of this article.

Ethical approval The study was approved by the Local Institutional Review Board, University of Cologne (No: 20-1369).

Informed consent Not applicable.

Open Access This article is licensed under a Creative Commons Attribution 4.0 International License, which permits use, sharing, adaptation, distribution and reproduction in any medium or format, as long as you give appropriate credit to the original author(s) and the source, provide a link to the Creative Commons licence, and indicate if changes 
were made. The images or other third party material in this article are included in the article's Creative Commons licence, unless indicated otherwise in a credit line to the material. If material is not included in the article's Creative Commons licence and your intended use is not permitted by statutory regulation or exceeds the permitted use, you will need to obtain permission directly from the copyright holder. To view a copy of this licence, visit http://creativecommons.org/licenses/by/4.0/.

\section{References}

1. Scheiderer B, Imhoff FB, Kia C et al (2019) LUCL internal bracing restores posterolateral rotatory stability of the elbow. Knee Surg Sports Traumatol Arthrosc 28:1195-1201. https://doi.org/ 10.1007/s00167-019-05632-x

2. Dehlinger F, Franke S, Hollinger B (2012) Therapeutic options for acute and chronic elbow instability. Eur J Trauma Emerg Surg 38:585-592. https://doi.org/10.1007/s00068-012-0205-y

3. Anakwenze OA, Kancherla VK, Iyengar J et al (2014) Posterolateral rotatory instability of the elbow. Am J Sports Med 42:485491. https://doi.org/10.1177/0363546513494579

4. Charalambous CP, Stanley JK (2008) Posterolateral rotatory instability of the elbow. J Bone Jt Surg Br 90:272-279. https://doi.org/ 10.1302/0301-620X.90B3.19868

5. O'Driscoll SW, Bell DF, Morrey BF (1991) Posterolateral rotatory instability of the elbow. J Bone Jt Surg Am 73:440-446

6. Cohen MS, Hastings H 2nd (1997) Rotatory instability of the elbow. The anatomy and role of the lateral stabilizers. J Bone Jt Surg Am 79:225-233

7. Conti Mica M, Caekebeke P, van Riet R (2016) Lateral collateral ligament injuries of the elbow-chronic posterolateral rotatory instability (PLRI). EFORT Open Rev 1:461-468. https://doi.org/ 10.1302/2058-5241.160033

8. Hackl M, Bercher M, Wegmann K et al (2016) Functional anatomy of the lateral collateral ligament of the elbow. Arch Orthop Trauma Surg 136:1031-1037. https://doi.org/10.1007/ s00402-016-2479-8

9. Hackl M, Heinze N, Wegmann K et al (2016) The circumferential graft technique for treatment of multidirectional elbow instability: a comparative biomechanical evaluation. J Shoulder Elbow Surg 25:127-135. https://doi.org/10.1016/j.jse.2018.11.047

10. Bernholt DL, Lake SP, Castile RM et al (2019) Biomechanical comparison of docking ulnar collateral ligament reconstruction with and without an internal brace. J Shoulder Elbow Surg 28(11):2247-2252. https://doi.org/10.1016/j.jse.2019.04.061

11. Dargel J, Boomkamp E, Wegmann K (2017) Reconstruction of the lateral ulnar collateral ligament of the elbow: a comparative biomechanical study. Knee Surg Sports Traumatol Arthrosc 25:943-948. https://doi.org/10.1007/s00167-015-3627-3

12. Dargel J, Burkhart K, Pennig D et al (2013) Percutaneous lateral ulnar collateral ligament reconstruction. Knee Surg Sports Traumatol Arthrosc 21:450-455. https://doi.org/10.1007/ s00167-015-3627-3

13. Bodendorfer BM, Looney AM, Lipkin SL et al (2018) Biomechanical comparison of ulnar collateral ligament reconstruction with the docking technique versus repair with internal bracing. Am J Sports Med 46:3495-3501. https://doi.org/10.1177/03635 46518803771

14. Ellwein A, Füßler L, ferle M (2020) Suture tape augmentation of the lateral ulnar collateral ligament increases load to failure in simulated posterolateral rotatory instability. Knee Surg Sports Traumatol Arthrosc 29:284-291. https://doi.org/10.1007/ s00167-020-05918-5

15. Jones CM, Beason DP, Dugas JR (2018) Ulnar collateral ligament reconstruction versus repair with internal bracing: comparison of cyclic fatigue mechanics. Orthop J Sports Med. https://doi.org/10. $1177 / 2325967118755991$

16. Jones KJ, Dodson CC, Osbahr DC et al (2012) The docking technique for lateral ulnar collateral ligament reconstruction: surgical technique and clinical outcomes. J Shoulder Elbow Surg 21:389393. https://doi.org/10.1016/j.jse.2011.04.033

17. Kim BS, Park KH, Song HS, Park SY (2013) Ligamentous repair of acute lateral collateral ligament rupture of the elbow. J Shoulder Elbow Surg 22:1469-1473. https://doi.org/10.1016/j.jse.2013.06. 018

18. King GJ, Dunning CE, Zarzour ZD et al (2002) Single-strand reconstruction of the lateral ulnar collateral ligament restores varus and posterolateral rotatory stability of the elbow. J Shoulder Elbow Surg 11:60-64. https://doi.org/10.1067/mse.2002.118483

19. Melbourne C, Cook JL, Della Rocca GJ et al (2020) Biomechanical assessement of lateral ulnar collateral ligament repair and reconstruction woth or without internal brace augmentation. JSES Int 4(2):224-230. https://doi.org/10.1016/j.jseint.2020.01.011

20. Dugas JR, Walters BL, Beason DP et al (2016) Biomechanical comparison of ulnar collateral ligament repair with internal bracing versus modified Jobe reconstruction. Am J Sports Med 44:735-741. https://doi.org/10.1177/0363546515620390

21. Greiner S, Koch M, Kerschbaum M et al (2019) Repair and augmentation of the lateral collateral ligament complex using internal bracing in dislocations and fracture dislocations of the elbow restores stability and allows early rehabilitation. Knee Surg Sports Traumatol Arthrosc 27:3269-3275. https://doi.org/10.1007/ s00167-019-05402-9

22. Wolfe S, Pederson W, Kozin SH et al. (2016) Green's operative Hand Surgery, 2-Volumen Set (7). Elsevier, Amsterdam: 734-832

23. Ott N, Harland A, Knevels M, Hackl M, Leschinger T, Lanzerath F, Scaal M, Wegmann K, Müller LP (2021) The role of the brachialis muscle in elbow stability with collateral ligament injury: a biomechanical investigation. Clin Biomech 6(89):105478. https:// doi.org/10.1016/j.clinbiomech.2021.10547

24. Fraser GS, Pichora JE, Ferreira LM et al (2008) Lateral collateral ligament repair restores the initial varus stability of the elbow: an in vitro biomechanical study. J Orthop Trauma 22(9):615-623. https://doi.org/10.1097/BOT.0b013e3181886f37

Publisher's Note Springer Nature remains neutral with regard to jurisdictional claims in published maps and institutional affiliations. 